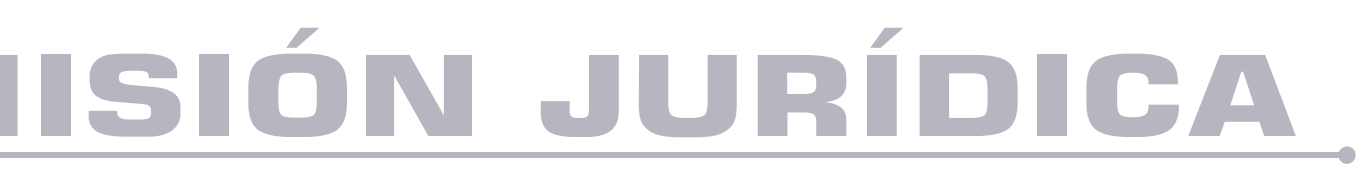

\title{
La Auditoría Ambiental, origen, desarrollo y evolución
}

The environmental auditing, origin, development and evolution

Autores: Alcides Antúnez Sánchez, Amed Ramírez Sánchez DOl: https://doi.org/10.25058/1794600X.1049

\footnotetext{
SP MISIÓN JURÍDICA A 


\title{
LA AUDITORÍA AMBIENTAL, ORIGEN, DESARROLLO Y EVOLUCIÓN*
}

\author{
The environmental auditing, origin, development and \\ evolution \\ Auditoria ambiental, origem, desenvolvimento e \\ evolução
}

\section{Alcides Antúnez Sánchez ${ }^{\mathrm{a}}$ aantunez@udg.co \\ Amed Ramírez Sánchez ${ }^{b}$} amed@lex.uh.cu

Fecha de recepción: 26 de agosto de 2019 Fecha de revisión: 29 de agosto de 2019 Fecha de aceptación: 03 de septiembre de 2019

\section{RESUMEN}

DOI: https://doi.org/10.25058/1794600X.1049

Para citar este artículo:

Sánchez, A., y Ramírez, A. (2019). La auditoria ambiental, origen, desarrollo y evolucion. Revista Misión Jurídica, 12, (17). 205-221.

Los avances en la política ambiental y en la gestión ambiental en las empresas del sector empresarial han permitido articular estrategias de conservación y aprovechamiento de los recursos naturales y del ambiente como paradigma del desarrollo sostenible ante los embates del cambio climático. Avances inclusivos al desarrollo normativo desde el texto constitucional hasta las materias administrativa ambiental para su protección, donde se establecen derechos ambientales y la participación ciudadana a partir de su reconocimiento en los conclaves internacionales. Se ejecuta el análisis y caracterización de la auditoría ambiental entre los instrumentos de mercado dentro de la formula estimulación/recompensa, vinculados al control público ambiental ejecutado por la Entidad Fiscalizadora Superior, a partir de su génesis, definición, desarrollo y evolución desde el siglo XX al XXI dentro cuerpo del artículo en relación con los problemas ambientales.

\section{*Artículo de reflexión}

a. Máster en Asesoría Jurídica mención Derecho Ambiental por la Universidad de Oriente. Profesor Auxiliar carrera de Derecho. Facultad de Ciencias Económicas y Sociales. Universidad de Granma. Cuba.

b. Máster en Derecho Constitucional por la Universidad Internacional Menéndez Pelayo y el Centro de Estudios Políticos y Constitucionales. Madrid, España. Máster en Derecho Constitucional y Administrativo por la Universidad de Oriente, Cuba. Profesor Auxiliar de Derecho Administrativo, Universidad de la Habana. Doctorando en Derecho Administrativo. 


\section{PALABRAS CLAVES}

Ecocompetencia, ecoeficiencia, evolución, fomento, control.

\begin{abstract}
Progress in environmental policies and environmental management of companies in the private sector have allowed for the articulation conservation strategies and utilization of natural and environmental resources as a sustainable development paradigm against the impact of climate change. Inclusive advances of legal development from the constitutional text to environmental administrative matters for its protection where environmental rights and citizen participation are included since their recognition in international summits. In this investigation an analysis is carried out along with characterization of environmental auditing among the instruments of the market within the stimulation/reward formula associated with environmental public control executed by the Superior Audit Body as of its genesis, definition, development and evolution since XX and XXI centuries regarding environmental problems.
\end{abstract}

\section{KEY WORDS}

Eco-competence, eco-efficiency, evolution, promotion, control.

\section{RESUMO}

Os avanços na política ambiental e a gestão ambiental nas empresas do setor de negócios permitiram articular estratégia de conservação e uso dos recursos naturais e do meio ambiente como paradigma do desenvolvimento sustentável diante das mudanças climáticas. Avanços inclusivos para o desenvolvimento normativo, desde o texto constitucional até as questões administrativas ambientais para sua proteção, onde os direitos ambientais e a participação do cidadão são estabelecidos com base em seu reconhecimento em conclaves internacionais. A análise e caracterização da auditoria ambiental são executadas entre os instrumentos de mercado dentro da fórmula de estímulo / recompensa, vinculada ao controle ambiental público executado pela Instituição Superior de Auditoria, com base em sua gênese, definição, desenvolvimento e evolução desde o século XX a XXI no corpo do artigo em relação a problemas ambientais.

\section{PALAVRAS-CHAVE}

Eco competência, eco eficiência, evolução, promoção, controle.

\section{INTRODUCIÓN}

El medio ambiente, ha sido asumido a lo largo de la evolución del "pensamiento filosófico y gnoseológico" del hombre como ser social de diferentes maneras y diversas acepciones. El hombre en su relación con la naturaleza y a fin de lograr la conservación de las condiciones ambientales que requiere para su hábitat sin perjuicio del desarrollo de las actividades económicas que lo impactan, necesita establecer los mecanismos, medidas y procedimientos que permitan una convivencia armónica de lo natural, de lo social y de lo económico. Al surgir la gestión ambiental, la aplicación de los instrumentos de tutela ambiental para su adecuada protección y dentro de la mismas, son los instrumentos o herramientas de gestión. Por ello, el desarrollo tecnológico y las nuevas tecnologías no pueden ser depredadoras del medio ambiente. El Derecho, se instituye como el medio para favorecer su desenvolvimiento ambiental responsable, con el uso de los instrumentos de comando y control como también se le conoce.

Sin embargo, paralelamente al extraordinario progreso científico y tecnológico, el que ha permitido un alto nivel de vida en las sociedades desarrolladas hoy más que nunca se advierten los innumerables riesgos originados por el propio desarrollo tecnológico y sobre los que, pese a dicho progreso sigue presente la incertidumbre científica sobre los efectos al medio ambiente y a la salud humana, de aquí la necesidad de la pertinencia de los principios del Derecho Ambiental que informan.

La aparición de la auditoría ambiental dentro de los mecanismos de control significó un escalón superior en el orden de integralidad, apuntó no solo a la eficiencia económica sino a la conformación de la empresa responsable con el ambiente. Representó impulsar y verificar el debido engranaje optimización, legitimidad, racionalidad y competitividad a las formas de gestión que la ponderan. Se inserta este tipo de auditoría entre los factores de estimulación de las fórmulas empresariales correspondiente a la resolución de la contradicción eje de los modelos económicos: ilimitadas necesidades individuales y colectivas y limitados recursos materiales disponibles para satisfacerlas, a partir de un desarrollo sostenible (fórmula/recompensa). 
Material y métodos:En el artículo se realiza una caracterización de la auditoría ambiental a partir de su génesis, desarrollo, evolución y reconocimiento jurídico, en relación con los problemas ambientales globales con incidencia del sector empresarial industrial para lograr el desarrollo sostenible, en los dos decenios del siglo XXI. Para ello, se han utilizado métodos como el de análisis síntesis, histórico lógico, inducción deducción, revisión bibliográfica, y el de comparación jurídica.

\section{Orígenes del control. Nexo con la contabilidad y la auditoría en su tracto histórico}

Los orígenes de la auditoría se remontan al Egipto antiguo, donde los soberanos para evitar desfalcos en las cuentas de sus residencias o en la construcción de obras públicas aplicaban medidas de control. Esta práctica estuvo presente en las civilizaciones antiguas y desapareció junto con el mercado, y el sistema monetario al finalizar esta etapa histórica y comenzar la Alta Edad Media, caracterizada por el predominio de la economía natural. (Villardefrancos Álvarez, et al. 2006: 53-59).

Para hablar de contabilidad y mucho menos de auditoría, no es pertinente hasta la época posterior a la invención de la escritura. Su práctica data de civilizaciones tan antiguas como la egipcia, en la que se procedía a controlar los ingresos de los impuestos y los gastos, subdividiendo la tarea entre recaudadores distintos, conociendo cada uno de ellos que su labor sería revisada con posterioridad por un funcionario distinto, para determinar el honesto manejo de los mismos como por los recaudadores encargados de estas funciones. En esta época, el pueblo era sometido al pago de tributos a quien lo dominaba, se conoce como contribución (impuesto); para su control se designaban revisores, quienes realizaban la actividad de fiscalización para la administración de sus riquezas, se evidencia en la civilización del pueblo Sumerio, en los años 3300 antes de Cristo.

En Centroamérica este antecedente se aprecia en México, donde el pueblo Azteca se caracterizó por la dominación de otros pueblos, actividad que hacían mediante la contribución con la figura de recaudador $\mathrm{o}$ auditor.

En Europa, en las naciones de Inglaterra y Escocia en 1130 se comenzó el uso de los llamados Registros de los Erarios, como una especie de registro contable. Se signa que el título de Auditor fue para las personas que dominaban esa técnica, iniciándose las asociaciones de estos profesionales en el Colegio de Contadores de Venecia, los Consejos Londinenses y el Tribunal de Cuentas de París.

Gran Bretaña, al decir de Barreiro, 1922, en sus estudios "la inspección de cuentas o libros data de época muy remota. En el año 1299, según se lee en los archivos del Ayuntamiento de Londres, se nombraba una persona que ejercía el cargo de Auditor o Inspector para que revisara las cuentas de aquel Municipio" (Zabala, 1922: 4).

En el resto de los países europeos, se introdujeron estos medios de control en la época del Renacimiento. A partir del siglo XII, en el período de Baja Edad Media, trajo consigo el resurgimiento de las ciudades, el florecimiento de los oficios y el desarrollo del comercio, los que exigían determinados tipos de evidencia documental en la actividad mercantil. (Villardefrancos Álvarez, et al. 2006: 53-59).

Ballesteros \& Marín-Baldo, 1924 son del criterio que, hacia el siglo XIII; se generaliza el uso del papel, aquí en este momento histórico, pudo obtener la contabilidad sensibles progresos. Más tarde, ya avanzado el siglo XVII, la Ordenanza francesa de 1673, perfiló la obligación de conservar y transcribir en un libro los aspectos contables, formulando semestralmente los inventarios. En España, país que cuenta con la legislación sobre el tema analizado más antigua del mundo, dispone la obligatoriedad para todos los comerciantes y banqueros, nacionales o extranjeros, residentes en los reinos de Castilla, de llevar sus cuentas per el sistema de partida doble. Así, las cosas, el origen de la auditoría es corroborado en el Tribunal de Cuentas, y se remonta a los tiempos de Sancho IV, el Bravo, Rey de Castilla y León (1284-1295), pocos años después surgía en Navarra bajo el reinado de Carlos II, el Malo, una institución de características similares, donde la Cámara, especie de consejo real para asuntos económicos tuvo facultades como Tribunal de Cuentas. (Martínez García, 1992: 62).

El motivo de la creación de estas instituciones jurídicas, como las Cortes de Toledo, celebradas en 1436, era auditar las cuentas públicas por los Contadores Mayores en el fondo el despilfarro público el que acaban pagando los contribuyentes por medio de los impuestos. El antecedente 
de esta evidencia se aprecia en el año 1328, en las Cortes de Medina del Campo cuando se pidió al Rey Alfonso XI el continuo aumento de los impuestos, con un mayor control del gasto público. (Martínez García, 1992: 62).

Siguiendo este estudio para caracterizar la función auditora, a finales del siglo XIII y principios del XIV ya se auditaban las operaciones de los funcionarios públicos que tenían a su cargo los fondos del Estado para su control. En Italia, en el siglo XV, surgieron las técnicas de teneduría de libros como el medio de mantener los ingresos y los gastos bajo el control público. El referente de la obra de Lucas Paccioli, 1494, tratado sobre el método conocido de la "partida doble", evidencia que desde el año 254 se inspeccionaban y comprobaban las cuentas, factor que permitió la evolución paralela de la actividad de la auditoría como resultado de la práctica de la contabilidad como ciencia, y a la vez como herramienta de trabajo de los especialistas dedicados a la contabilidad con el desarrollo del comercio. (Tua Pereda, 2008: 1-23).

Para 1799, ya existían firmas acreditadas de contadores públicos en Escocia, Estados Unidos de América e Inglaterra, fueron las primeras naciones en las que toma relevancia la contaduría pública ligada a la práctica de la auditoría pública. Adoptaron el modelo británico de información, lo mismo que sus procedimientos analíticos. (Tua Pereda, 2012: 94-110), (Saldoval Morales, 2012: 10-23).

Gironella Masgrau (1976: 15) señala que la historia refiere que existían unos controles recaudatorios en otras civilizaciones, en el Imperio Chino y Mesopotamia. No obstante, el autor consultado indica que la auditoría tal como se concibe actualmente, como una función de validación de los estados financieros, nació en los inicios del siglo XIX en Gran Bretaña. Por ello, desde las ciencias contables, se aprecia en este análisis que los estudios refieren que la práctica de la auditoría nace en la primera mitad del siglo XIX, luego se extendió a países de la cultura empresarial anglosajona como la forma de hacer fiable la información contable, permitió la transparencia del mercado de valores ante el desarrollo económico y la expansión de las relaciones económicas al exigirse información precisa y real de sus estados de cuentas, para dar confianza y competitividad a la actividad comercial. (Villardefrancos Álvarez, et al. 2006: 53-59).
La razón de ser Gran Bretaña la cuna de la institución jurídica de la auditoría, se explica por ser el país pionero en la Revolución Industrial, precursor y máximo exponente de las técnicas de auditoría en su desarrollo, cuestión que se debe a dos causas, por un lado: al alto nivel del desarrollo industrial y financiero, y haber contado con la experiencia de siglos de los llamados Consejos Londinenses, precursores de las actuales asociaciones profesionales de auditores. (Villardefrancos Álvarez, et al. 2006: 53-59).

En Roma, también se aprecian evidencias que se practicó una especie de control preventivo en la administración de los fondos públicos, siendo en la época del Imperio de Augusto, años antes del nacimiento de Jesucristo, cuando alcanza su plenitud. Los romanos recaudaban sus tributos por medio de sus cuestores, que a su vez rendían cuentas al tesorero central de Roma.

A manera de cierre de este momento histórico, ilustran los elementos estudiados que, el acto de rendir cuentas supone la existencia de un principio de contabilidad crítica: el examen por un funcionario superior de las operaciones económico-financieras realizadas por otro funcionario de inferior categoría, a fin de otorgarles su aprobación o desestimarlas. (Blanco, 1980: 74).

Hasta el suceso histórico de la Revolución Industrial, se demuestra que la economía se desarrollaba en base a una estructura de empresa familiar donde la propiedad y la dirección de sus negocios confluían en las mismas personas, que no sentían ninguna necesidad de la auditoría independiente ni tampoco se les imponía por normativa legal. Como acontecimiento económico social del siglo XIX, fue el suceso histórico cultural que demandó la participación de hombres especializados en analizar los problemas económicos, financieros y contables para su evaluación, donde se necesitó de la contaduría pública como la herramienta técnica para estos fines. (Kuhn, 2001: 1-36), (Méndez-Gutiérrez Del Valle, 2009: 55-56).

Suarez (1990: 3) considera desde su postura que la auditoría tal como hoy en día se concibe, en su acepción restringida o verdadera auditoría, consiste en la comprobación de la veracidad de la información contable, no nace en Europa hasta después de la revolución industrial; en pleno siglo XIX, tuvo un desarrollo muy desigual en 
unos y otros países inicia su irradiación. Ilustra sobre la función de auditor, al observar que en España se le denomina "Auditor de Rota" a cada uno de dos doce prelados del tribunal romano de la Rota, que tiene jurisdicción para conocer en apelación de las causas eclesiásticas; auditor conventual, al religioso encargado de examinar las cuentas del monasterio; auditor militar, al funcionario del cuerpo jurídico-militar que informa sobre la interpretación y aplicación de las leyes y propone la resolución correspondiente en los procedimientos judiciales instruidos por el ejército; Auditor de la marina, al juez letrado que entiende en las causas del fuero del mar; Auditor canónico, a la persona designada instructor en las causas canónicas. En los países de cultura latina, y en particular en España, el uso de esta palabra quedó relegada hasta comienzos del siglo XX en el Derecho Militar y el Derecho Canónico.

\section{Desarrollo, aplicación y perfeccionamiento de la función auditora en la gestión pública ambiental en el siglo $\mathrm{XX}$}

En el siglo XX para su perfeccionamiento $\mathrm{y}$ desarrollo, fueron incluidas normas jurídicas a la auditoría como voluntad de la Administración Pública, permitió que se fortaleciera el trinomio Contabilidad, Auditoría y Derecho, al cobrar nuevas dimensiones como norma administrativa para proteger los activos contra posibles transgresiones, tipificándose con la protección del bien jurídico ambiental y otras infracciones, ubicados bajo el término genérico de los delitos ambientales con reflejo en la contabilidad directa o indirecta a los sujetos de gestión, fortalecida con el uso de las herramientas de las Tecnologías de la Informática y las Comunicaciones (Tic) en la contabilidad como su nexo vinculante.

El aporte con una gran visión de futuro, realizado desde el Derecho Mercantil por Vicent Chulia (2005), al señalar al control contable, como el término verificación y la expresión de auditoría. Otra es la idea aportada por Broseta Pons (2010: 292), al referir sobre la censura de cuentas es una denominación castellana, y auditoría de cuentas es la denominación importada de la práctica anglosajona. De aquí que se visualice su nexo con el Derecho, y en especial con el Derecho Mercantil.

Vinculado al estudio de la función de la auditoría, Rodríguez Flores De Quiñones (1964:
169), explicita, para quien los juristas y hace la referencia a España, ignoran la contabilidad, minimizan su importancia y no tienen presentes las bases fundamentales de esta disciplina al tratar de solucionar los problemas que plantean en esta materia. Este elemento ha influido en la jurisprudencia de los Tribunales y se ha reflejado en la legislación, que con frecuencia contienen errores en materia contable. La doctrina contable desconoce en la mayor parte de los casos, los principios más esenciales de la ciencia del Derecho y de la hermenéutica jurídica.

Lo reafirma en su postura Vicent Chulia (2005), quien manifesta que la contabilidad y el derecho van en un divorcio histórico. Aunque se reconoce que la correcta actualización de la contabilidad es manifestación de una buena organización empresarial y el Derecho Mercantil la ha fomentado tradicionalmente mediante el reconocimiento de los asientos contables como una prueba privilegiada. Por la transversalidad del tema, la auditoría tiene reflejo desde el Derecho Internacional Público, al ser su paraguas, irradiándolo hacia el Derecho Administrativo y al Derecho Constitucional, le dan fuerza jurídica para su desarrollo en cuerpos jurídicos dentro de los ordenamientos jurídicos.

En esta misma cuerda, aparece la auditoría ambiental dentro de los mecanismos de control público, significó un escalón superior en el orden de integralidad, porque apuntó no solo a la eficiencia económica sino a la conformación de la empresa responsable con el ambiente. Representó impulsar y verificar el debido engranaje optimización, legitimidad, racionalidad y competitividad a los sujetos de gestión que la ponderan. Elementos que han sido pertinentes y han permitido que haya evolucionado la auditoría ambiental con el transcurso del tiempo en relación con el país que la aplique y el desarrollo tecnológico industrial que posea en su desarrollo normativo. Su conexión está relacionada a los orígenes del ius ambientalismo como parte de la Agenda Pública Internacional. Las Entidades Fiscalizadoras Superiores (EFS) señalan al año 1969, como su inicio. Se inserta este tipo de auditoría entre los factores de estimulación de fórmulas empresariales correspondiente a la resolución de la contradicción eje de los modelos económicos: ilimitadas necesidades individuales y colectivas y limitados recursos materiales disponibles para satisfacerlas a partir 
del desarrollo sostenible. Donde como tradición la relación entre la empresa y medio ambiente ha sido bastante conflictiva: los principales daños ambientales los acarrea la empresa y esta ha percibido la atención al medio ambiente como un obstáculo en sus actividades y un freno para su desarrollo. (Loperena Rota, 2003: 57-73), (Allí Aranguren, 2006: 1-34).

Se le conoce a la auditoría ambiental con varios nombres en la literatura científica, como "ecoauditoría", "revisión ambiental", "control ambiental", "evaluación ambiental", "vigilancia ambiental", etc., aunque su significado resulta ser el mismo. Dentro de la familia de los instrumentos de comando y control ambiental, los ordenamientos jurídicos, por su origen idiomático, su cultura y su realidad económico-social, consideran que es capaz de evaluar y sentar las bases de una política ambiental dirigida a los empresarios. Se vincula a los conceptos de economía y contabilidad ambiental creados por el PNUMA.

No obstante, se considera atinado hacer referencia a la "teoría del control", en autores que han realizado aportes como Cabanellas de Torres (2006) quien considera "...el término del control es mejor reconocerle como comprobación, fiscalización, intervención, registro, vigilancia, mando, gobierno, predominio, hegemonía, supremacía, dirección, guía, freno, contención, regulador, factor, causa..."

Para Toledo Cartes el control es:

(...) coincidente con la acepción que le asignan normativas de organismos profesionales de cobertura mundial, relacionados con la materia. En efecto, su idea central es la de dirección, gestión, conducción de todas las actividades que propendan a lograr los objetivos propuestos por la dirección superior de las organizaciones. lo que también implica la idea esencial de control preventivo (2003: 4).

Su naturaleza jurídica, está concebida a partir de que el control es un sistema de verificación y corrección de la legalidad que evalúa el principio de juridicidad, directamente vinculado al concepto de Estado de Derecho, y ciertamente se relaciona con la democracia como forma política de gobierno nacional. En el marco de un Estado de Derecho, el control implica que la Administración Pública en su organización, funcionamiento, relaciones con la comunidad y su personal están subordinados al ordenamiento jurídico como sujeto pasivo, el que deriva directamente de un marco constitucional. Las normas jurídicas deben someterse a la Constitución Política, y a estas deberán someterse a su vez, las normas que se derivan de la potestad reglamentaria.

En el Derecho Público, el control para Márquez Gómez (2005)

(...) es una herramienta y a la vez una técnica. Es instrumental toda vez que juridifica las conductas impuestas como obligatorias a los agentes sociales, en especial a los agentes de la sociedad, en particular a sus servidores públicos al imponerle márgenes de actuación que los convierte en sujetos obligados y por ende en objetivos de control por excelencia. Como técnica, el derecho delimita los procesos, métodos y formas de actuación de los entes controlados cuando estos ejecutan sus actividades (p. 48).

La INTOSAI (1953), organismo mundial de control, concebida como la organización encargada de fiscalizar la regularidad de las cuentas y la gestión financiera pública, es una organización no gubernamental con status especial en el Consejo Económico y Social de las Naciones Unidas, es una organización autónoma y apolítica, ha concebido

(...) el control no representa una finalidad en sí mismo, sino una parte imprescindible de un mecanismo regulador que debe señalar oportunamente las desviaciones normativas y las infracciones de los principios de legalidad, rentabilidad, utilidad y racionalidad de las operaciones financieras, de tal modo que puedan adoptarse las medidas correctivas convenientes en cada caso, determinarse la responsabilidad del órgano culpable, exigirse la indemnización correspondiente o adoptarse las determinaciones que impidan o por lo menos, dificulten la repetición de tales infracciones en el futuro (Canales, 2009: 43).

Tradicionalmente, la relación entre la empresa y el medio ambiente ha sido conflictiva: los principales daños ambientales los acarrea la empresa y esta ha percibido la atención al medio ambiente como un obstáculo en sus actividades y un freno para su desarrollo y para la creación de empleos. Han sido los principales factores que ha obligado a la empresa como sujeto económico, a replantearse su actitud estratégica hacia el medio ambiente, ante la creciente preocupación social a 
raíz de la magnitud de la crisis ambiental global, como fruto de la actividad económica insostenible.

Sanz Larruga señala en este sentido:

Paralelamente al extraordinario progreso científico y tecnológico que ha permitido un alto nivel de vida en las sociedades desarrolladas hoy, más que nunca, se advierten los innumerables riesgos originados por el propio desarrollo tecnológico y sobre los que, pese a dicho progreso, sigue existiendo una considerable incertidumbre científica sobre sus efectos sobre el medio ambiente y la salud humana (2011: 1-288).

La auditoría ambiental, se instrumenta en los países de mayor desarrollo industrial a través de metodologías y técnicas en sus ordenamientos jurídicos. Su ordenación se vincula a elementos históricos, teóricos, doctrinales, legislativos y culturales con la práctica de la auditoría y la contabilidad social, ligados a la responsabilidad social a partir de 1953 en los Estados Unidos de América. (Kreps, 1940: 1-2), (Bowen, 1953: 7-47), (Romanque, 1996: 133-160), (García Fronti, 1997: 55-77)

En la década de los 70 del siglo pasado, se señala al empresariado norteamericano como los primeros en aplicarla de manera voluntaria para evaluar la empresa con la finalidad de servir como herramienta de dirección para la gestión ambiental, todo ello debido al aumento y la complejidad de la normativa jurídica Estadual y Federal en su ordenamiento jurídico, ante los problemas ambientales que acontecían generados por la contaminación y que habían originado problemas en el orden legal. (Harrison, 1996:1-676). Estos elementos han obligado a los empresarios a replantearse una actitud estratégica hacia el medio ambiente, con una actitud proambiental para hacer competitiva la empresa en el mercado.

Las EFS creadoras de este tipo de auditoría, le concedieron la función de dar a conocer los índices de contaminación generados como resultado de la producción industrial de bienes y servicios y estimular la implementación de las tecnologías limpias, los sistemas de gestión ambiental $y$ otros instrumentos en materia contable, para obtener la certificación ambiental a partir de la década de los 90' del pasado siglo. Se concibe que, implementar la auditoría ambiental fue una respuesta estratégica para modificar los hábitos de consumo y estilos de vida contrarios al desarrollo sostenible, como el efecto negativo del desarrollo tecnológico y las transformaciones económico-sociales. Trajo como resultado, el reto de crear instrumentos y herramientas que viabilizaran su aplicación y permitieran el equilibrio entre los avances tecnológicos y el medio ambiente.

Desde las ciencias jurídicas, en el Derecho Ambiental Internacional, la auditoría ambiental es reconocida como una herramienta de gestión dentro de los instrumentos de tutela ambiental, es utilizada para minimizar los impactos ambientales negativos generados por la actividad humana, y a su vez como una estrategia de la Administración Pública para proteger el bien jurídico público ante la problemática del cambio climático; tiene vínculo con otras herramientas de gestión como la Evaluación de Impacto Ambiental, la Inspección Ambiental y la Licencia Ambiental, entre otras. (Juste, 1999: 37-49).

Por la transdisciplinariedad de la institución jurídica analizada, constituye un reto al exigir la responsabilidad a los actores económicos en la protección al bien jurídico ambiente como un bien de uso público, acorde a el acatamiento del principio de legalidad, ratificada en la Cumbre de Río en 1992, Johannesburgo en 2002, y en la Agenda 2030, donde el control público ambiental es tema pertinente, de aquí que su principal reconocimiento sea en cada país a través del texto constitucional y se desarrolle en los ordenamientos en normas jurídicas especiales. (Jordano, 1995: 50), (Soler, 2016: 5-190).

En la propia década de los 90', en su desarrollo, se le adicionan nuevos elementos tecnológicos vinculados al Comercio Internacional, la hacen mucho más compleja, completa y dinámica en cuanto a la gestión ambiental por parte de los sujetos económicos que la implementan; las técnicas, métodos y objetivos como actividad de control de forma simétrica evolucionó para poder atender y dar respuestas a las nuevas exigencias de los clientes a partir del siglo XX. (Bracamontes Aldana, 1994: 111-149), (Polar Falcón, 1999: 4958), (Mora Ruiz, 2005: 127-129).

Al ser introducida por las EFS en 1995, como una herramienta de gestión ambiental, aunque otros estudios desde las ciencias contables consideren que su génesis está vinculada a la 
contabilidad y a la auditoría social para dar respuesta a problemas generados al medio ambiente con la contaminación atmosférica, por el vertido, la lumínica, la sonora, la protección a la biodiversidad, el cambio climático, a los recursos hídricos, al incremento de los niveles de radiación, a la lluvia ácida, por el incremento de las concentraciones de ozono generado por la industria, la mala calidad del aire en las ciudades, el uso y manejo de la tierra, la desertificación, el comercio y el medio ambiente. Cuestión aún por esclarecerse. Puntualizan que permite realizar la evaluación sistemática, documentada, periódica y objetiva de la efectividad de la organización auditada en la gerencia para proteger el bien jurídico público ambiente con un mejor control de las prácticas ambientales y la evaluación para cumplir la política ambiental de la empresa y las normas legales a partir de la institucionalización de la tutela ambiental. (Elstein, 2012: 17-45).

La Cámara Internacional de Comercio, dentro de las Naciones Unidas en 1986 la reconoce como la

(...) herramienta de gestión que comprende una evaluación sistemática, documentada, periódica y objetiva del funcionamiento de la organización ambiental. Prevé la implantación de gestión, así como los equipos de control necesarios con objeto de facilitar el control de gestión de las prácticas medio ambientales y declarar la observancia de la política de la Compañía de acuerdo con la normativa ambiental. Es el examen metódico que implica análisis y comprobaciones de las prácticas y procederes ambientales de una empresa o parte de ella. Este término de auditoría es sinónimo de revisión y verificación de diversos aspectos de una empresa (Belmonte Martin, 2009: 56-78).

Las normas técnicas ambientales ISO 14 001:1995, la definen como el "proceso sistemático, autónomo y documentado para obtener evidencias de la auditoría, evalúa de manera objetiva con el fin de determinar la extensión en que se cumplen los criterios de auditoría” (Lannelongue Nieto, 2011: 43).

La Asociación Americana de Contabilidad la concibe como:

(...) el proceso sistemático para obtener y evaluar de manera objetiva las evidencias relacionadas con informes sobre actividades económicas $\mathrm{y}$ otros hechos relacionados. Su finalidad consiste en determinar el grado de correspondencia del contenido informativo con las evidencias que le dieron origen para determinar si en dichos informes se han elaborado con la observancia de los principios establecidos para el caso (Alvarado, 2014: 15).

En Iberoamérica, estudios realizados desde las ciencias contables por González Malaxechevarría (1997: 40-53), Gray, Bebbinton \& Walters (1999), Páez (2001), Lorena Barilá (2002), Woliski (2009), Fronti De García \& García Casella (2003), Mejía (2010), Herreras Aristi, et. al. (2014) refieren que ha ido en evolución con el aumento de su espectro de actuación; empero, para su ejecución precisa de la contabilidad ambiental para registrar el hecho económico de forma indirecta o directa para el seguimiento y el control de los elementos que afectan la sostenibilidad ambiental en una forma de gestión, lo hace con un nuevo pensamiento contable desde lo teórico, epistemológico y metodológico para aplicarla por los servidores públicos, está vinculada con la tributación ambiental y el seguro ambiental. La auditoría ambiental, pondera el principio de rendición de cuentas como lo explícita Moneva \& Lamedo (2004: 1-27); al ser un derecho de la sociedad, permite conocer el impacto de las actividades que todo sujeto de gestión económica tiene en su comunidad y con el entorno para actuar de manera sostenible y respetuosa con su entorno (Martin Mateo, 1994).

También, en la propia década de los 90' empiezan a publicarse estudios desde las ciencias jurídicas, reflejan el análisis de la política pública ambiental con la aplicación de herramientas de gestión para determinar los niveles de contaminación, exigir la responsabilidad, aplicar la evaluación ambiental estratégica, la cuantificación del daño, los servicios públicos ambientales, la inspección ambiental, los permisos ambientales, el uso de las tecnologías limpias, los sistemas de gestión ambiental y la obtención de la certificación ambiental para lograr beneficios en el comercio, y el uso de la ecoetiqueta para la protección del consumidor como un derecho vinculados a la praxis de la auditoría ambiental. (Sanz Rubiales, 2000), (Verdes Cabarcos, 2014).

Se demuestra, que la ejecución del control ambiental por la EFS se conjuga la competitividad y la sostenibilidad en un equilibrio adecuado con el medio ambiente, al ponderar la norma técnica ISO 26000 en pos del desarrollo sostenible. 
Permite evaluar el compromiso de la gestión ambiental con el medio ambiente a la empresa y la industria. (Fernández De Gatta Sánchez, 2004: 1-19), (Sales de Freitas, 2013: 309).

La obra jurídica de autores iberoamericanos como Martín Mateo (1991), Nogueira López (1997), Brañes Ballesteros (2000), Loperena Rota (2003), Esteve Pardo (2002), Gordillo (2006), Embid (2008), señalan que la auditoría ambiental está articulada a una actividad de control, evalúa al sujeto de gestión de manera voluntaria u obligatoria, es concebida como una fórmula de autorregulación ambiental con efecto público externo, no es un servicio público típico, en su ejecución son aplicadas normas técnicas ambientales ISO 14 000, 19 011, 26000 y el Sistema Comunitario de Gestión y Auditoría Medioambientales (EMAS) para el sector industrial, tiene naturaleza jurídica pública y de fomento ambiental, concebida dentro de la fórmula estimulación-recompensa, con efecto directo y vinculante al auditado, puede ser onerosa o gratuita, y su resultado final es certificatorio de la gestión ambiental del auditado. Se vincula al Derecho Ambiental con el principio de prevención, precautorio, de quien contamina paga, de responsabilidad, de cooperación, y de legalidad; como instrumento de carácter corrector, mejora el comportamiento ambiental al auditado, es interdisciplinaria y puede tener un carácter punitivo. (Fernández De Gatta Sánchez, 2004), (Caferrata, 2009), (Antúnez Sánchez, 2015). Fernández, C. parafraseando a Parejo Alfonso, reseña:

(...) actualmente vivimos en una época de cierta preocupación política, institucional y privada por la situación del medio ambiente. La valoración social de las cuestiones ambientales ha cambiado profundamente en las últimas décadas del siglo $\mathrm{XX}$ y los primeros años del siglo XXI, en general hacia posiciones de una mayor concienciación por la calidad del medio ambiente, ante la eventual sexta extinción que se avecina y cuyo culpable son las conductas inadecuadas originadas por el hombre (2004: 27).

Se colige que, la Administración Pública en su gestión pública vinculada a la función auditora, implementa técnicas de fomento, caracterizadas por el respeto de la libertad de los destinatarios, estimula la actuación de estos concorde con los intereses generales al proponerles incentivos -normalmente económicos (subvenciones)que faciliten esa actuación protectora al medio ambiente. Las técnicas en ejecución son variadas, pero en el ámbito del medio ambiente se limitan a ayudas económicas, aquí aparecen las ecoauditorías y las ecoetiquetas como herramientas de mercado en la fórmula estimulación/recompensa dentro de la cláusula de progreso técnico en la actividad de la contratación mercantil, y se actualiza con los avances científicos. (Martin Mateo, 1993: 494-495), (Nogueira López, 2000: 5-17), (Dopazo, 2001: 21).

Fernández de Gatta Sánchez arguye sobre la contaminación en el sector empresarial industrial

(...) a causa de la creciente degradación del medio ambiente ha traído consigo que las empresas e industrias comiencen a utilizar nuevos instrumentos de protección ambiental, aunque sean de carácter voluntario, en el contexto de una nueva ética empresarial. Desde hace algunos años surge el concepto de Responsabilidad Social Corporativa, para referirse al proceso mediante el cual dichas empresas deciden voluntariamente contribuir al logro de una sociedad mejor y de un medio ambiente más limpio. Junto a esta línea de actuación, han surgido otros instrumentos que, asimismo, deben integrarse en esta nueva ética empresarial (Fernández, 2004: 27).

Desde las ciencias empresariales, se aprecian los aportes desde varios saberes, evidencian la integración de contenidos en la actividad de control estudiada desde la ingeniería, la química, las ciencias ambientales, la física, las matemáticas, ente otras disciplinas; Gómez (1994), Ruesga, et al. 1995), Conesa Fernández-Vitora (1997), Seoanez Calvo, et al. (1999), Viña Vizcaíno (2003), Rodríguez Córdova (2016), señalan que la auditoría ambiental verifica el comportamiento ambiental de una empresa o industria, se implementa a través de un sistema de gestión ambiental de acuerdo con las normas técnicas ISO 14 000, 14050, 19 011, 26 000, $90000 \mathrm{y}$ en Europa con el EMAS. Es voluntaria u obligatoria para mejorar el comportamiento ambiental al auditado en relación con sus activos ambientales. Se inserta en el principio, según el criterio en que "lo verde, vende". En algunas naciones la ejecuta el Ministerio del Ambiente al sector privado y la Contraloría General al sector público, o las formas privadas concesionadas. En atención a que evalúa la gestión ambiental, ha sido concebida como aquellas actividades técnicas y organizativas que realizan las empresas para reducir el impacto ambiental que generan sus operaciones y su objetivo es conseguir un desarrollo ambiental 
sostenible (Gupta, 1980), con eficiencia, eficacia y economía, pertinentes con el cumplimiento del principio de legalidad. (Cramer, 1998).

Foy señala en este análisis

La gestión ambiental es un concepto -como en muchas de las temáticas ambientales- polisémico cuyo contenido en parte dependerá del enfoque disciplinario que se le confiera. Sin embargo, cada vez más hay un consenso al tomar como referencia el vocabulario de la norma técnica ISO 14050 , que no lo define como tal sino -mejor aún- como sistema de gestión ambiental (Foy, 2008: 1)

Todo el análisis, estudio y caracterización, se percibe que los sistemas contables tradicionales buscan informar la situación financiera $y$ patrimonial del sujeto auditado, la información ambiental se orienta a dar cuenta de las acciones para lograr un desarrollo sostenible, con un análisis más cualitativo que cuantitativo; surge la necesidad de establecer los fundamentos metodológicos para un marco conceptual relacionado con el medio ambiente debido a la complejidad de armonizar esta información con los estados financieros de los sujetos de gestión. (Larrinaga, 1999), (Masanet, 2005), (Choy Zevallos, 2014).

Por ello, se justiprecia que luego de analizadas estas posturas desde las ciencias contables, las jurídicas, y las empresariales, se puede colegir que el tratamiento jurídico contable y empresarial de esta actividad de control, su reconocimiento legal, al ser evaluadora de la contabilidad ambiental de los estados financieros en sus activos ambientales a los sujetos de gestión, de su naturaleza jurídica evaluadora de la gestión ambiental sigue en construcción, desarrollo y evolución en el siglo XXI, para alcanzar el mega principio del desarrollo sostenible. El equipo auditor en su ejecución usa las normas técnicas ambientales. Se exige la responsabilidad ambiental al vulnerarse la legalidad como principio, tal y como lo han referido (Nogueira López, 2000), (Rodríguez Campos-González, 2003), (Méndez, 2009), (Mora Ruiz, 2012), (López Donaire, 2013), (Antúnez Sánchez, 2018).

Ligado al mercado de bienes y servicios, dentro de la fórmula estimulación-recompensa, Bas \& Herson refieren desde las ciencias empresariales:
(...) en la gestión ambiental que hoy conocemos, se ha construido mediante la interacción de un complejo conjunto de factores económicos, sociales, culturales, políticos y ambientales. En muchos países, sobre todo en los de mayor desarrollo industrial, se habían tomado en cuenta los aspectos ambientales en la planificación institucional, aunque de manera fragmentada, principalmente en las leyes relativas a las aguas y las obras públicas, pero es a partir de la publicación "The National Environmental Policy Act" (NEPA) aprobada en 1970 (1993: 13).

La auditoría ambiental responde a las necesidades sociales, por ello en la Cumbre de Johannesburgo en 2002 se pondera su uso a escala global como su paraguas. Es la herramienta de gestión susceptible de integrarse por su transversalidad en la realización de las revisiones clásicas establecidas por otras ramas de la economía industrial, integrada a otros tipos de auditorías -legalidad, financiera, cumplimiento, gestión- al revisar en sus programas aspectos vinculados con la protección ambiental con una visión estratégica, aplicando la inteligencia ecológica para ello. (Goleman, 2010: 1-16).

La auditoría ambiental, brinda a los empresarios una mejor información en materia ambiental como meta hacia la sostenibilidad para desarrollar la empresa responsable con el ambiente. Se tutela por la Administración Pública con un fin: preservar el bien jurídico ambiental. Es interdisciplinaria, transdisciplinaria, multidisciplinaria y multidimensional como parte de un nuevo saber ambiental en el nuevo pensamiento ambiental de América Latina, al ser reconocida la naturaleza como sujeto de derechos en el Pluralismo jurídico De Jure. (Aguilar e Iza, 2005: 25-29), (Villavella Armengol, 2012: 51-76), (Díaz Ocampo y Antúnez Sánchez, 2018: 1-20).

Para la auditoría ambiental, ni las normas ni el referente doctrinal son homogéneos en lo concerniente a los indicadores a medir, la significación de los mismos, ni cómo hacerlo atendiendo a las diferencias del desarrollo tecnológico y las formas de gestión económica. Los ordenamientos jurídicos no han tenido en cuenta los diferentes momentos de control "no solo a la tecnología existente sino a la que se va adquirir" como mecanismo de prevención. Desde los diversos saberes de manera indistinta se le define. No obstante, las ventajas de aplicación parten de 
la observancia de los principios de precaución y prevención con un adecuado autocontrol en la organización auditada, permite a los empresarios promocionar la gestión ambiental y direccionar estratégicamente la actividad productiva hacia formas eficientes y competitivas, pero aún necesita una adecuada formación ambiental para obtener educación ambiental ante los nuevos saberes ambientales como es el desarrollo sostenible, reconocido en 1987 en el informe Bruntdland. (Sanz Larruga, 2016).

$\mathrm{Al}$ ejecutarse la auditoría ambiental por la EFS, convergen el control y la protección ambiental de forma permanente, pero no pueden estar divorciadas de la dinámica económica y de la fórmula Investigación + Desarrollo + Comercio en función del desarrollo sostenible en el mercado internacional con ecocompetencia, donde las EFS a nivel global y regional juegan un rol en lograr el equilibrio entre el progreso y la protección ambiental para las futuras generaciones con el control a la ecoinovación, los permisos negociables y el mercado de emisiones de $\mathrm{CO}^{2}$ dentro de las técnicas de mercado en la gestión ambiental integrada que en el siglo XXI, pertinentes para los empresarios europeos al crear valores ambientales. (Fusler, et al. 1999), (Arteaga, 2015).

De aquí, que también sea evaluado dentro del proceso de la auditoría ambiental, el tema de la "economía circular", vinculada a los recursos naturales limitados y a la creciente contaminación creada por la generación de residuos para implementar medidas para que estos productos no sean desechados sino reutilizados o reciclados para crear nuevos productos por las empresas e industrias. Pertinente con los objetivos del milenio para el 2030 -objetivo 12 "producción y consumo sostenible"-. (Lozano, 2015). Lleva a estudiar la posición de Touraine quien señala "la empresa deja de ser considerada como la expresión concreta del capitalismo y, aparece cada vez más como una unidad estratégica en un mercado internacional competitivo y como un agente de utilización de tecnologías nuevas" (Touraine,1993: 186).

Ante este análisis, las empresas en un marco generalizado de preocupación ambiental del que se hace eco el propio ordenamiento ambiental, han asumido conciencia del impacto de sus actividades industriales con el ambiente y su posición proactiva en el mantenimiento y mejora del entorno con una visión estratégica. Las empresas aceptan el principio de responsabilidad objetiva, lo que conlleva una serie de obligaciones tanto para limitar el impacto de su actividad sobre el ambiente para garantizar su competitividad. (Aragón Correa, 1998), (Ludevid, 2000), (Heras, et al. 2008), (Belmonte Martin, 2009).

\section{La evolución de la auditoría ambiental en el siglo XXI en el control público}

La evolución de la auditoría ambiental en el siglo XXI, ha sido desde el primer decenio, al transitar hacia la auditoría de gestión cooperada ejecutada en la región de la Amazonía por las EFS en América Latina a los recursos hídricos, a la biodiversidad y al cambio climático, a través de acciones evaluadoras a las políticas públicas y al marco regulatorio ambiental. Se aprecia muta del control clásico del sistema empresarial hacia el medio ambiente. Su régimen jurídico utiliza instituciones jurídicas del Derecho Administrativo como la autorización, la concesión administrativa y el dominio público, todas evalúan el principio de juricidad a través de la gestión ambiental compartida. (Elstein, 2012: 15), (Lustosa Da Costa, 2014: 43-46), (Antúnez Sánchez, 2015: 1-25).

La auditoría de gestión ambiental responde a los objetivos económicos, de utilidad, factibilidad, eficacia, reducción de costos, ganancias; los sociales, crecimiento cualitativo y cuantitativo, competitividad, pleno empleo, reducción de riesgos para la vida; y los ecológicos, se dirigen a la utilización económica de los recursos y al mantenimiento del equilibrio y protección del entorno. En la auditoría de gestión ambiental, de acuerdo con la perspectiva de las normas técnicas ambientales ISO, mantienen los principios básicos de la auditoría y los de la contabilidad, pero requiere de un auditor que maneje los aspectos específicos de la gestión ambiental en el sujeto económico a auditar, de aquí que en su ejecución perviva la transdisciplinariedad en la conformación del grupo de auditores. Por ello es superior a la auditoría ambiental tradicional, este es otro cambio en su evolución. De aquí que, se analice la postura de Jaquenod De Zogön al expresar que "el hombre contemporáneo se enfrenta como depredador de la naturaleza, sin tomar conciencia que, en más o menos medida, forma parte de ella, está acogido por ella, y al desnaturalizarla y alterarla, el mismo se desnaturaliza, altera y traiciona su propia esencia" (1991: 352). 
Empero, por el grado de conocimiento no adecuado del tema, a partir de que el medio ambiente es reservado para ecologistas, aun y cuando existen instituciones interesadas en debatir y protegerlo, hay sujetos de gestión que cuando se interrelacionan con el entorno no le asignan la importancia que reviste al ser objeto de control ambiental; de aquí la necesidad de la formación jurídico ambiental a partir de la integración de contenidos, agravada con el cambio climático, ponderado desde la Cumbre de la Tierra+20 en 2012 Río de Janeiro y en la XXI Conferencia Internacional sobre cambio climático en 2015 en la ciudad de Paris. (Rey Santos, 2016: 7-173), (Antúnez Sánchez, 2018: 1-17).

Antúnez Sánchez (2017: 1-35) concibe que la auditoría ambiental como actividad de control es un instrumento de gestión ambiental de naturaleza jurídica pública, sus campos de acción son la empresa, la industria y el medio ambiente (personas jurídicas y naturales) dentro de la formula estimulación-recompensa, su ejecución es realizada por funcionarios públicos requeridos de título profesional y título habilitante, registrados en el Registro de Auditores y Contralores; su función es evaluadora y certificadora de las metas ambientales en relación con la política ambiental trazada por la organización empresarial, es una técnica de comprobación de la legalidad con una potestad reglada de la Administración Pública. Es un proceso, en su práctica se utilizan procedimientos y metodologías, en ella se evalúa la ejecución gasto contable del patrimonio destinado a la protección ambiental, puede ser ejecutada de forma interna o externa, se evalúa la eficiencia del sistema de gestión ambiental en relación con el vertido, la introducción de tecnologías limpias en la organización empresarial, se aplican normas técnicas, se exige la responsabilidad administrativa contravencional, laboral-funcionarial, social-empresarial, civil y penal a los sujetos auditados. Tiene efecto directo $\mathrm{y}$ vinculante al auditado, puede ser onerosa o gratuita. Su resultado final certificatorio le aporta valores añadidos que inciden de forma positiva en el comercio y el mercado a la persona jurídica o natural objeto de la auditoría.

Evidencian estos elementos estudiados que a pesar de la vasta teorización sobre la auditoría ambiental, aún su construcción conceptual, su regulación y práctica adolece del enfoque sistémico para el logro de la empresa responsable con el ambiente, está necesitada de integración de contenidos entre las diferentes ciencias y saberes para este propósito; hoy con la aparición dentro de la $4^{\text {ta }}$ Revolución Industrial de la Industria 4.0, y los posturas internacionales sobre la Agenda para el desarrollo sostenible 2030, están necesitadas del acompañamiento desde una visión estratégica por los empresarios esta institución jurídica sigue en evolución y desarrollo en los ordenamientos jurídicos que la reconocen, este es el segundo momento evolutivo del control público en la web 2.0.

La evolución en el siglo XXI de la auditoría ambiental con el uso de las Tic en la web 2.0, implementarse herramientas digitales en este sentido. Se valora que tiene nexo con las herramientas informáticas al ser utilizadas en la contabilidad, en el comercio electrónico, el uso de la firma electrónica, con la ventanilla única de certificación ambiental dentro del gobierno digital, al ponderar el principio de información, entre otras. La auditoría ambiental, es útil compararla con la auditoría financiera, como su antecedente próximo inmediato dentro de las ciencias contables al estar vinculadas con el análisis contable-financiero a los actores económicos. Ambas auditorías, la ambiental y la financiera, deben ser conducidas por auditores calificados según los niveles de acreditación, basados mayormente en la experiencia profesional, y en cierto grado, en el entrenamiento y calificación profesional de acuerdo a procedimientos sistemáticos, abarcan un examen o revisión de la actividad para verificar que los aspectos bajo su consideración se ajustan al ordenamiento especificado o planificado dentro del control a ejecutar, por un nexo empresa y medio ambiente (Durán Romero, 2007).

Presentado este panorama científico de la institución jurídica estudiada, luego de analizadas las posturas interdisciplinarias desde las ciencias sociales, la contabilidad, el derecho, las ciencias empresariales, las ciencias informáticas y las ciencias ambientales, evidencian el tratamiento jurídico, contable, ecológico y empresarial que ha tenido esta actividad de control público desde su reconocimiento legislativo en los ordenamientos jurídicos, ejecutada en una evaluación contable ambiental de los estados financieros de la industria y la empresa que la implementa, su naturaleza jurídica es evaluadora de la gestión ambiental al sujeto de gestión que la pondera para ser competitivo. 


\section{CONCLUSIONES}

La auditoría ambiental, en su caracterización ha permitido identificar los elementos siguientes:

Sobre el origen de lo que hoy se conoce desde la "teoría del control", se ha comprobado que la auditoría como actividad de control, tiene su génesis desde las antiguas culturas. Tuvo su mayor desarrollo en el continente europeo, lo que permitió e incidió en su irradiación como paraguas al resto de los continentes, desarrollándose en la medida del desarrollo industrial de cada nación.

\section{Su desarrollo en el siglo XX}

Estuvo centrada en la inclusión junto a las normas de contabilidad y las de auditoria, la apertura a las normas jurídicas. Al uso de las herramientas de las Tecnologías de la Informática y las Comunicaciones, para dar una respuesta estratégica ante la contaminación, ponderar el principio de legalidad, la aplicación de normas técnicas ambientales, la protección al consumidor (ecoetiqueta), la aplicación en el mercado con el marketing de "lo verde vende", la integración de contenidos en el control público por tener un carácter interdisciplinario, transdisciplinaria, multidisciplinaria y multidimensional, preconizar la Investigacion+Desarrollo+Comercio con el uso de tecnologías limpias, la aplicación de la responsabilidad objetiva ante el daño ambiental, y la valoración económica de la calidad ambiental.

Es regulada como una actividad de control, es un instrumento de gestión ambiental de naturaleza jurídica pública, su campo de acción son la empresa, la industria y el medio ambiente (personas jurídicas y naturales) dentro de la formula estimulación-recompensa, su ejecución es realizada por funcionarios públicos requeridos de título profesional y título habilitante, registrados en el Registro de Auditores y Contralores con diversas denominaciones en los modelos estudiados; su función es evaluadora y certificadora de las metas ambientales en relación con la política ambiental trazada por la organización empresarial, es una técnica de comprobación de la legalidad con una potestad reglada de la Administración Pública.

Es concebida como un proceso, en su práctica se utilizan procedimientos y metodologías, en ella se evalúa la ejecución gasto contable del patrimonio destinado a la protección ambiental, puede ser ejecutada de forma interna o externa, se evalúa la eficiencia del sistema de gestión ambiental en relación con el vertido, la introducción de tecnologías limpias en la organización empresarial, se aplican normas técnicas, se exige la responsabilidad administrativa contravencional, laboral-funcionarial, social-empresarial, civil y penal a los sujetos auditados. Tiene efecto directo y vinculante al auditado, puede ser onerosa o gratuita. Su resultado final certificatorio le aporta valores añadidos que inciden de forma positiva en el comercio y el mercado a la persona jurídica o natural objeto de la auditoría.

\section{En el siglo XXI}

En la Unión Europea, prevalece la función pública de tutela ambiental desde el texto constitucional, en su manifestación de control o actividad de policía. El EMAS, ha sido el salto en el control ambiental con la ecoauditoría, tiene como característica intrínseca ser un instrumento normativo de aplicación directa a los Estados miembros, sin perjuicio que cada Estado promulgue normas que faciliten su implementación de forma obligatoria, aunque también prevalece la forma voluntaria. Se pondera el principio ambiental de responsabilidad compartida, papel activo en la prevención de los riesgos que garanticen un control sistemático con el autocontrol, denominada gestión ambiental compartida. El sistema comunitario de ecogestión y ecoauditoría, constituye uno de los exponentes más complejos de una nueva técnica de intervención de los poderes públicos consistente en el fomento, la regulación y el control de la autorregulación privada.

En América Latina, la ecoauditoría se mueve con tres auditorías ambientales ejecutadas al medio ambiente, permitieron a la Administración Pública obtener información del comportamiento de las políticas públicas y de la normativa ambiental como paradigmas ambientales, permitió trazar estrategias que involucran a todos los actores que intervienen en la protección ambiental, desarrollar nuevas tácticas, recomendaciones, campañas de fomento de la cultura ambiental para alcanzar el desarrollo sostenible, distinguiéndola de los modelos de los Estados Unidos de América y el de la Comunidad Europea, al reconocerse como sujeto a la naturaleza dentro del Pluralismo Jurídico De Jure.

Su concepto, desarrollo, y evolución siguen en crecimiento dentro de la $4^{\text {ta }}$ Revolución Industrial 
con la Industria 4.0 con la transformación de la economía digital en la web 2.0 a partir de lograr empresas ecoeficientes, ecocompetentes para proteger al consumidor ecologista con ecoproductos a través del marketing ambiental ponderando la información a los consumidores como un derecho a través de la ventanilla única de certificación ambiental, la introducción de los permisos negociables en la contratación pública, en la gestión y la implementación de tecnología limpias, el tributo ambiental, el seguro ambiental en pos de alcanzar el desarrollo sostenible dentro de las adversidades que impone el cambio climático. Hay hoy predominio de la gestión pública-privada en el control dentro de la aplicación de la fórmula estímulo/recompensa con distinción entre la empresa y la industria, con un renovado Derecho Público.

Los elementos abordados permiten ponderar la necesidad de fomentar la formación jurídico ambiental a los servidores públicos que ejercitan el control público, proceso formativo que puede socializarse a través de folletos, apk; y concebirse desde la academia en talleres, cursos de posgrado (diplomados, especialidades, y maestrías), incidente en alcanzar una cultura ambiental adecuada, tributaria al desarrollo sostenible deseado como política pública del Estado.

\section{BIBLIOGRAFÍA}

- Antúnez, A. (2005). La auditoría ambiental en Cuba, Facultad de Derecho (Tesis de maestría). Universidad de Oriente.

- Antúnez, A. (2015). La auditoría ambiental: Una revisión y propuestas en clave de su función pública y dimensión empresarial. Revista Iberoamericana de Contabilidad de Gestión, (26).

- Antúnez, A. (2015). La auditoría de gestión ambiental a los recursos hídricos, a la biodiversidad y al seguimiento del cambio climático. Revista del Tribunal de Cuentas, (132).

- Antúnez, A. (2016). La gestión ambiental. Incidencia en el comercio. Revista Veredas do Direito Ambiental e desenvolvimiento sustentavel.

- Antúnez, A. (2017). La auditoría ambiental, ordenación jurídica en el Derecho Ambiental para el sector estatal cubano. (Tesis doctoral). Universidad de Oriente.

- Antúnez,A.(2018). La fórmula estimulación/ recompensa en el Derecho Administrativo Ambiental. Visión desde la administración estratégica por los sujetos de gestión. Revista de investigación y análisis De Jure, (91).

- Antúnez, A. (2018). La formación ambiental. Una necesidad en el siglo XXI con el nuevo saber ambiental. Revista Murmullos del Sur, UNAM.

- Antúnez, A. (2018). La ecoauditoría en el modelo de la Comunidad Europea y de América Latina. Revista de Derecho Ambiental, (55).

- Antúnez, A. \& Díaz, E. (2018). El pluralismo jurídico en América Latina. Revista Dos Tribunais Thomsonreuters, (990).

- Antúnez, A. et al. (2019). La Ventanilla Única de Certificación Ambiental en Panamá. Revista Derecho \& Paz, Brasil. (41).

- Alvarado, M. (2014). Teoría y práctica de la auditoría. España: Editorial Pirámide.

- Agenda 2030 (2018). Los objetivos de desarrollo sostenible. Una oportunidad para América Latina y el Caribe. Chile: CEPAL.

- Arteaga, K. (2015). Ecogestión y Ecoauditoría, un instrumento de protección medio ambiental, (Tesis de maestría). Universidad Complutense de Madrid.

- Alfonso, J. (2008). Modelo de gestión de la responsabilidad social corporativa directa. (Tesis doctoral). Universidad de Pinar del Río.

- Bass, R. \& Herson, A. (1993). Mastering NEPA: a step-by-step approach. Solano Press Books, Point Arena, California, USA.

- Barreiro, L. (1922). Los Chartered 
Accountant. España : Editorial Artes Gráficas Grijelmo.

- Barilá, G. (2002). Auditoría ambiental: El camino hacia el logro de una ventaja competitiva. Argentina: Universidad de Belgrano.

- Ballesteros, M. \& Marín-Baldo, L. (1924). Tratado completo de contabilidad (s/e). Barcelona.

- Brañes, R. (2001). Informe del Derecho Ambiental en Latinoamérica, análisis histórico-doctrinal y jurídico desde el Derecho Ambiental. México: $1^{a}$ edición, PNUMA.

- Brañes, R. (2000). Informe sobre el desarrollo del Derecho Ambiental Latinoamericano. Su aplicación después de diez años dela Conferencia de las Naciones Unidas sobre el medio ambiente y el desarrollo. México: PNUMA.

- Blanco, J. (1980). Régimen jurídico de la contabilidad de los empresarios (s/e). Madrid.

- Bowen, H. (1953). La responsabilidad social de los empresarios. La auditoría, vínculos con otras ciencias y saberes. Estados Unidos de América.

- Belmonte, I. (2009). La ecoauditoría: un instrumento para la defensa del ambiente. Revista de la Facultad de Ciencias Sociales y Jurídicas de Elche. (4).

- Broseta, M. (2010). Manual de Derecho Mercantil. Madrid: Editorial Tecnos.

- Bracamontes, J. (1994). Marco legal de las auditorías ambientales en el mundo. La protección ambiental con la combinación de legislación, regulación y políticas voluntarias a la industria. México: UNAM.

- Cabanellas de Torres, G. (2006). Diccionario Jurídico Elemental. Perú: Editorial Heliasta.

- Caferrata, N. (2013). Análisis del marco regulatorio en los países de América Latina y el Caribe. Economía verde en el contexto del desarrollo sostenible y erradicación de la pobreza. PNUMA.

- Caferrata, N. (2009). Teoría de los principios del Derecho Ambiental. Revista Abeledo Perrot.
- Callejón, M. (2007). Innovación y política pública: hacia una nueva política económica de innovación. Revista sobre la Sociedad del Conocimiento, (4).

- Camacho, G. (2000). Los principios de eficacia y eficiencia administrativa. Argentina: Editorial Conosur.

- Canales, J. (2009). Documentos básicos para la modernización y el fortalecimiento de las Administraciones Públuias en Iberoamérica. Alicante: Club Universitario.

- Conesa Fernández-Vitora, V. (1997). Auditorías medio ambientales: guía metodológica. España: Editorial Mundi-Prensa.

- CEPAL. (2016). Horizontes 2030: la igualdad en el centro del Desarrollo Sostenible. México.

- Chulia F. (2005). Introducción al Derecho Mercantil. Valencia: Editorial Tirant Lo Blanch, 18 a edición.

- Durán, G. (2007). Empresa y medio ambiente. Políticas de gestión ambiental. Madrid: Editorial Pirámide.

- Dopazo, P. (2001). El régimen jurídico de las marcas de calidad ambiental. Etiqueta ecológica y tutela ambiental. Madrid: Editorial Exlibris.

- Esteve, J. (1999). La adaptación de las licencias a la mejor tecnología disponible. Revista de Administración Pública, (149).

- Esteve, J. (1999). Técnica, Riesgo y Derecho: Tratamiento del riesgo tecnológico en el Derecho Ambiental. Barcelona: Editorial Ariel.

- Esteve, J. (2002). Autorregulación: Génesis y efectos. Pamplona: Editorial Aranzadi.

- Esteve, J. (2003). Principio de precaución. El derecho ante la incerteza científica. Revista Jurídica de Catalunya, (3).

- Elstein, S. (2012). La auditoría del medio ambiente crece y evoluciona para afrontar los retos de un ambiente cambiante. Revista de Auditoría Gubernamental, INTOSAI.

- Embid, A. (2008). El derecho a un medio ambiente adecuado. Madrid: Editorial Iustel. - Fernández De Gatta, D. (2004). Auditorías y 
Sistemas de Gestión Ambientales en la Unión Europea: Evolución, régimenvigenteyperspectivas futuras, Noticias UE, $\mathrm{N}^{\circ} 228$, España.

- Fernández, C. (2004). El marco conceptual de la contabilidad ambiental. Una propuesta para el debate. Revista Contabilidad y Auditoría,(19).

- Foy, P. (2008). Consideraciones Legales sobre la Guía de Auditoría Ambiental Gubernamental, Empresa y Ambiente, Actualidad Gubernamental №. 11, Perú.

- Fronti de García, L. et al. (2003). Auditoría ambiental, un nuevo enfoque profesional. Buenos Aires: Universidad de Argentina.

- Heras, I. et al. (2008). Evolución de la adhesión del EMAS en la Unión Europea y España. España:Editorial Ambienta.

- García, I. (1997). El problema ambiental y su repercusión en el paradigma de utilidad de la contabilidad patrimonial o financiera. Contabilidad y Auditoría. Facultad de Ciencias Económicas. Universidad de Buenos Aires. No. 6 Argentina.

- Gray, R., Bebbington, J. \& Walter, D. (2007). Contabilidad y auditoría ambiental. Colombia: Editorial ECOE, $1^{\text {a }}$ edición.

- Gupta, N. (1980). Some alternative definitions of size. USA: Academy of Management Journal, № 4,

- Gómez, D. (1994). Auditoría ambiental: un instrumento de gestión en la empresa. Madrid: Editorial Agrícola.

- González Malaxechevarría, Á. (1997). Auditoría Ambiental. Su evolución histórica y entorno político institucional. Hacia una nueva perspectiva: La auditoría financieroambiental. Madrid: Editorial Ortega.

- González, M. \& Fernández De Gatta Sánchez, D. (2009). Legislación sobre el Cambio Climático. Madrid: Editorial Tecnos.

- Gordillo, A. (2006). Tratado de Derecho Administrativo, (control de la empresa pública). Argentina: Editorial Macchi, $8^{\text {va }}$ edición.

- Goleman, D. (2010). Inteligencia ecológica. Barcelona: Editorial Kairos.
- Gironella, E. (1976). El control interno y la censura de cuentas. España: Editorial ICE.

- Kreps, T. (1940). Measurement of the social performance of business. $\mathrm{N}^{\circ}$. 7-8, Economic Committee, USA.

- Páez, J. (2001). Una exploración empírica de los factores que condicionan la actitud frente a la contabilidad ambiental. Revista de Contabilidad, (7).

- Jaquenod De Zsögön, S. (1991). El Derecho Ambiental y sus principios rectores. Madrid: Editorial Dykinson, 3aㅡ edición.

- Juste, J. (1999). Derecho internacional del Medio Ambiente. Madrid: Editorial McGraw Hill.

- Jordano, J. (1995). La protección del derecho a un medio ambiente adecuado. Barcelona: Editorial José María Bosch.

- Kuhn, T. (2001). La estructura de las revoluciones científicas. Madrid: Editorial Fondo de Cultura Económica.

- Lannelongue, G. (2011). Esfuerzo y eficacia en los sistemas de gestión ambiental de empresas certificadas ISO14001 (s/e) Salamanca.

- López Donaire, M. (2013). El impacto del derecho medio ambiental en la empresa: hacia una nueva regulación jurídico administrativa, (Tesis doctoral). Universidad Castilla- La Mancha.

- Loperena, D. (2003). Desarrollo sostenible y globalización. Argentina: Editorial Thomson-Aranzadi.

- Lozano, B. (2015). Tratado de Derecho Ambiental. España: Editorial CEF, $1^{\text {a }}$ edición.

- Ludevid, M. (2000). La Gestión Ambiental de la Empresa. Barcelona: Editorial Ariel.

- Lustosa Da Costa, C. (2014). Las auditorías coordinadas y sus contribuciones para los Estados Federales: la experiencia de la auditoría en la Amazonía. Revista OLACEFS, (15).

- Martín, R. (1991). La ecoauditoría. España: Boletín de Estudios Económicos, № 150.

- Martínez,F. (1992). La regulación dela Auditoria en España. Antecedentes, pasado reciente y situación actual. Madrid: Editorial ICJCE.

- Márquez, D. (2005). Función jurídica 
del control de la Administración Pública, Instituto de Investigaciones Jurídicas. México: UNAM.

- Mora, M. (2005). Responsabilidad compartida en la gestión ambiental (Tesis doctoral). Universidad de Huelva.

- Méndez Gutiérrez Del Valle, R. (2009). Teoría de las revoluciones industriales. Revista del Ministerio de Fomento.

- Mejía, E. (2010). Contabilidad ambiental, crítica al modelo de contabilidad financiera. Colombia: Editorial Optigraf.

- Moneva Abadía J. \& Lameda Montero I. (2004). Sostenibilidad vs rentabilidad en las grandes empresas españolas. La contabilidad sin fronteras. España: Universidad de Granada.

- Nogueira, A. (2000). Ecoauditorías, intervención pública ambientaly autocontrol empresarial. España: Editorial Marcial Pons.

- Nogueira, A. (1997). Régimen jurídico de la auditoría ambiental, (Tesis doctoral). Universidad Santiago de Compostela.

- Polar, E. (1999). La Contabilidad Medioambiental. Revista Quipucamayoc, Lima.

- Rey, O. (2016). Derecho y cambio climático, legislando en un mundo cambiante. La Habana: Editorial Academia.

- Rodríguez Córdova, R. (2016). La auditoría ambiental en la gestión empresarial, Editorial Colciencias, Holguín.

- Rodríguez-Campos, S. (2003). El fomento de la ecoauditoría como estrategia interventora. Madrid: Editorial Thomson Civitas.

- Rodríguez J. \& Alcaide A. (2013). Auditoría Ambiental (s/e). España.

- Rodríguez, F. (1964). En torno a las relaciones entre la contabilidad y el derecho fiscal. España: Editorial de la Cámara Oficial de Comercio e Industria de Granada.

- Rodríguez, A. (2016). Teoría y práctica del buen vivir: orígenes, debates conceptuales y conflictos sociales. el caso de Ecuador, (Tesis Doctoral). Universidad del País Vasco.

- Romanque, D. (1996). El Contador y su Rol en la Empresa Ambientalmente Responsable. Revista Ambiente y Desarrollo, (1).

- Ruesga, S. et al. (1995). Empresa y Medio Ambiente. España: Editorial Pirámide.

- Sanz, I. (2000). Sobre la naturaleza jurídica de la etiqueta ecológica. España: Editorial Marcial Pons.

- Sanz, F. (2016). Derecho Ambiental para una economía verde. España: Editorial Aranzadi.

- Saldoval, H. (2012). Introducción a la auditoría. México: Editorial Red tercer milenio, $1^{\text {a }}$ edición.

- Sales, R. (1999). Auditoría Ambiental, aspectos jurídicos. Brasil: Editorial Malheiros.

- Sales de Freitas, J. (2013). Auditoría externa ambiental como instrumento de defensa del medio ambiente. Revista De Jure, (20).

- Soler, I. (2016). La configuración constitucional del medio ambiente como derecho, (Tesis doctoral). Universidad de Valencia.

- Suarez, A. (1990). La moderna auditoria, análisis conceptual y metodológico. Madrid: Editorial McGraw-Hill de Management.

- Toledo, J. (2003). El control interno de la administración: modernización de los sistemas como una emergencia. $2^{\circ}$ Congreso Internacional del CLAD sobre la Reforma del Estado y de la Administración Pública, Panamá.

- Tua, J. (2008). Evolución y situación actual del pensamiento contable. La inserción de la contabilidad ambiental en la empresa. Revista Legis de Contabilidad \& Auditoría, (24).

- Tua, J. (2012). Pacioli la partida doble y el renacimiento. Revista de Contabilidad, España.

- Villardefrancos, M. (2006). La auditoría como proceso de control: concepto y tipología. Revista Ciencias de la Información, (2).

- Villavella, C. (2012). El Derecho constitucional del siglo XXI en Latinoamérica: un cambio de paradigma. Estudios sobre el nuevo constitucionalismo latinoamericano. Valencia: Editorial Tirant lo Blanch. 